\title{
Fluorescent Immunoassays for Detection and Quantification of Cardiac Troponin I: A Short Review
}

\author{
Remya Radha, Syeda Kiran Shahzadi ${ }^{\dagger}$ and Mohammad Hussein Al-Sayah *D \\ Department of Biology, Chemistry, and Environmental Sciences, American University of Sharjah, \\ Sharjah 26666, United Arab Emirates; rradha@aus.edu (R.R.); kiran.syyed@gmail.com (S.K.S.) \\ * Correspondence: malsayah@aus.edu \\ + Current address: Department of Basic Medical Sciences, Mohammad Bin Rashid University of Medicine and \\ Health Sciences, Dubai 505055, United Arab Emirates.
}

check for updates

Citation: Radha, R.; Shahzadi, S.K.; Al-Sayah, M.H. Fluorescent Immunoassays for Detection and Quantification of Cardiac Troponin I: A Short Review. Molecules 2021, 26, 4812. https://doi.org/10.3390/ molecules26164812

Academic Editor: Rafael Chinchilla

Received: 2 July 2021

Accepted: 5 August 2021

Published: 9 August 2021

Publisher's Note: MDPI stays neutral with regard to jurisdictional claims in published maps and institutional affiliations.

Copyright: (C) 2021 by the authors. Licensee MDPI, Basel, Switzerland. This article is an open access article distributed under the terms and conditions of the Creative Commons Attribution (CC BY) license (https:// creativecommons.org/licenses/by/ $4.0 /)$.

\begin{abstract}
Cardiovascular diseases are considered one of the major causes of human death globally. Myocardial infarction (MI), characterized by a diminished flow of blood to the heart, presents the highest rate of morbidity and mortality among all other cardiovascular diseases. These fatal effects have triggered the need for early diagnosis of appropriate biomarkers so that countermeasures can be taken. Cardiac troponin, the central key element of muscle regulation and contraction, is the most specific biomarker for cardiac injury and is considered the "gold standard". Due to its high specificity, the measurement of cardiac troponin levels has become the predominant indicator of MI. Various forms of diagnostic methods have been developed so far, including chemiluminescence, fluorescence immunoassay, enzyme-linked immunosorbent assay, surface plasmon resonance, electrical detection, and colorimetric protein assays. However, fluorescence-based immunoassays are considered fast, accurate and most sensitive of all in the determination of cardiac troponins post-MI. This review represents the strategies, methods and levels of detection involved in the reported fluorescence-based immunoassays for the detection of cardiac troponin I.
\end{abstract}

Keywords: cardiac troponin; myocardial infarction; immunoassays; fluorescence; biosensors; cardiovascular diseases

\section{Introduction}

Cardiovascular diseases (CVDs) are the leading cause of death in intensive care units worldwide, showing a significant increase in the number of heart failure-related hospitalization and becoming an emerging epidemic [1]. The World Health Organization expects the number of deaths due to CVDs to exceed 23 million by the year 2030 [2]. These diseases of the heart and blood vessels are related mainly to the build-up of plaque inside the arteries leading to atherosclerosis. One of the most life-threatening events of this blockage of arteries is acute myocardial infarction (MI) ("heart attack") which could cause irreversible damage to the heart tissues. Electrocardiography (ECG) is usually the diagnostic tool for MI [3], however, more than 40\% of MI cases show normal ECG when admitted to the emergency room. Additionally, in many cases, MI is asymptomatic without any apparent chest pain or shortness of breath leading to an even lower chance of being diagnosed directly [4]. To overcome the shortcoming of ECGs, the measurement of certain biomarkers in the blood of the patient provides a more accurate diagnosis of MI. Currently, creatine kinase-MB, myoglobin, cardiac forms of troponin $\mathrm{T}(\mathrm{cTnT})$, and cardiac troponin I (cTnI) are considered key biomarkers for diagnosis of MI with cTnT and cTnI as the gold standards among the three since they are highly specific to cardiac tissue injuries [4].

\section{Cardiac Troponin-A Biomarker for Myocardial Infarction}

Troponin is a complex of three proteins (Table 1) that regulate the contraction of skeletal and cardiac muscles; (i) Troponin I (TnI) inhibits the ATPase activity and binds to 
actin, (ii) Troponin C (TnC) binds to calcium ions and induce conformational changes in TnI, and (iii) Troponin $\mathrm{T}(\mathrm{TnT}$ ) attaches to tropomyosin forming Tn-tropomyosin complex $[5,6]$. The cardiac forms of TnI and TnT are significantly different from those of the skeletal muscles. In the event of MI, cTnI and cTnT are released from the injured heart muscles into the bloodstream and their concentration remains high over several days, even when no other symptoms of MI are present [7]. The normal concentration of $\mathrm{cTnI}$ is $1-2 \mathrm{ng} / \mathrm{mL}$ or less; after the onset of MI, the concentration of cTnI increases to about $50 \mathrm{ng} / \mathrm{mL}$ within 3-6 h reaching as high as $500 \mathrm{ng} / \mathrm{mL}$ [4]. Precise quantification of cTn levels in a patient's blood following ischemia/chest pain may indicate whether the patient had a myocardial infarction (MI) or not [8].

Table 1. Cardiac Troponin (cTn) subunits/role $[9,10]$.

\begin{tabular}{ccc}
\hline cTn Subunits & Molecular Weight and Size & Functions \\
\hline cTnI & $24 \mathrm{kDa}, 210$-residue long protein & Actomyosin ATPase inhibitory subunit \\
cTnT & $36 \mathrm{kDa}, 288$-residue long protein & Tropomyosin binding subunit \\
cTnC & $18 \mathrm{kDa}$ a 161-residue long protein with & $\mathrm{Ca}^{2+}$ binding subunit and an anchoring \\
& two globular domains & protein of Tn complex \\
\hline
\end{tabular}

\section{Immunoassays for cTnI Detection}

Over the last few decades, the use of immunoassays for clinical and research purposes has been given remarkable attention due to their ability to accurately detect specific antigen or antibody molecules within a short span of time. Since cTnI and cTnT characterize a unique $\mathrm{N}$-terminal amino acid sequence, the development of their specific antibodies and assays and, thus, detection of each component in the bloodstream became easier and acceptable [11].

There are different strategies used for the development of immunoassays, however, "sandwich" immunoassay is one of the most reported assay designs for detection of $\mathrm{cTnI}$ in the last few years. This assay design is based on capturing the targeted antigen between a "capture" antibody and a "detecting" antibody where each binds at a different and distant epitope. The capturing antibody is usually immobilized on a surface, which can be a microplate well, a paper surface (cellulose or nitrocellulose), a nanoparticle, or an electrode. The immobilization process provides a handle to separate the targeted antigen from the other components of the sample, which minimizes interference. The detection antibody is then introduced to bind to the antigen through its exposed molecular surface (epitope). The detecting antibody is associated with the signaling mechanism and signal amplification of the detection process. Different signaling mechanisms were reported and these include optical (colorimetric, fluorescence, emission), electrochemical, and magnetic signals, in addition to radioactivity and surface plasmon resonance (SPR) [4,12-27]. Signal amplification, however, is the process by which each antigen-binding (detection) event is translated into a large number of "signaling" molecules or probes to produce a read-out signal.

\section{Purpose and Scope}

A variety of assay types for $\mathrm{cTnI}$ with different signaling mechanisms were reported in recent years. Table 2 provides a summary of these assays with their mode of signal amplification, the limit of detection (LOD) and linear dynamic range (LDR). While LODs reflect the estimated lower concentrations (calculated at three standard deviations of blank), LDRs indicate the actual measurements of the assay and its relevancy to the measurements at the physiological concentration range.

This review is focused mainly on heterogeneous sandwich immunoassays for the quantification of $\mathrm{cTnI}$ using fluorescence as the output signal of detection. Based on the mechanism of fluorescent signaling, the assays reported over the last 5-7 years can be classified into three main categories. Accordingly, the detection antibody (Scheme 1) is either (i) directly conjugated with a fluorescent label, (ii) linked to a package of fluorescent labels, or (iii) linked to an enzyme that converts a quenched substrate to a fluorescent 
or a luminescent product. Hence, each binding/detection event of the antibody to the antigen is reflected through the fluorescence of the probe (as in (i)) or further amplified by increasing the concentration of the fluorescent probe for each binding event (as in (ii) and (iii)). The amplification process enhances the sensitivity and lowers the LOD but it may limit the range of detection due to signal saturation or self-quenching at high concentrations of the antigen. The ideal assay will have high sensitivity with LDR that matches the physiological concentration range of the antigen (for cTnI, concentrations are at $1-500 \mathrm{ng} / \mathrm{mL}$ ). Fluorescence signaling seems to provide a practical option that can offer sensitivity, a clinically relevant LDR, and the ability to develop a point-of-care system with minimal use of equipment.

Table 2. A summary of reported immunoassays for cTnI.

\begin{tabular}{|c|c|c|c|c|}
\hline Assay Type/Signaling Mechanism ${ }^{a}$ & Signaling Probe/Particle & LOD (ng/mL) & LDR (ng/mL) & Ref \\
\hline QDs-based SIA & Immunomagnetic microparticle and QDs & $4.7 \times 10^{-2}$ & $0-40$ & [28] \\
\hline PoC system by fluorescence detection & Sensor chip with fluorescence-labeled dAb & $6.2 \times 10^{-4}$ & $2.0-7132$ & [27] \\
\hline LFIA with fluorescent nanoprobe & $\begin{array}{l}\text { Multilayer surface-functionalized nanospheres with } \\
\text { fluorescent molecules. }\end{array}$ & $4.9 \times 10^{-2}$ & $0.049-50.0$ & [29] \\
\hline LED-excitation-based immunoassay for PoC use & A reflection-type fluorimeter with a single chip UV LED & $2.2 \times 10^{-4}$ & $0.25-30.0$ & [21] \\
\hline Fluorescent aptasensor & $\begin{array}{l}\text { Fluorescence of anti-cTnI aptamers labeled by } \\
\text { 6-carboxyfluorescein }\end{array}$ & $7.0 \times 10^{-2}$ & $0.1-6.0$ & [30] \\
\hline $\begin{array}{l}\text { Two-dimensional paper-based fluorescent } \\
\text { immunosensor }\end{array}$ & Fluorescent-conjugated $\mathrm{dAb}$ & $5.0 \times 10^{-2}$ & $0.05-25.0$ & [20] \\
\hline Extended SIA & Fluorescent-conjugated tertiary antibody & $1.0 \times 10^{-4}$ & $0.1-1.0$ & [31] \\
\hline FSIAwith MOF-loaded dye & Release of fluorescent coumarin from a MOF & $9.9 \times 10^{-5}$ & $0.00024-0.7911$ & [32] \\
\hline FSIA & $\begin{array}{l}\text { Sensitive fluorescent-europium } \\
\text { (III)-chelate-dye-nanoparticle }\end{array}$ & $2.0 \times 10^{-3}$ & $0.003-9.6$ & [33] \\
\hline RCA of fluorescent aptamer & $\begin{array}{l}\text { FRET signal between the fluorescent aptamer and } \\
\text { graphene oxide }\end{array}$ & $1.4 \times 10^{-2}$ & $0.050-0.5$ & [34] \\
\hline $\begin{array}{l}\text { Fluorometric and colorimetric dual-readout ALP } \\
\text { activity }\end{array}$ & $\begin{array}{c}\text { Hydrolysis of m-hydroxyphenyl phosphate to a } \\
\text { fluorescent product }\end{array}$ & $4.0 \times 10^{-2}$ & $0.125-8.0$ & [35] \\
\hline Enzymatic chemiluminescence and MIA & ALP chemiluminescence chemistry-based detection. & $1.0 \times 10^{-1}$ & $0.1-50.0$ & [36] \\
\hline ALP-based fluorescent ELISA & Fluorescent polymer carbon dots & 1.0 & $1.0-30.0$ & [37] \\
\hline NLISA & $\begin{array}{c}\text { Colorimetric and ratiometric fluorescent detection } \\
\text { through oxOPD and QDs }\end{array}$ & $2.3 \times 10^{-4}$ & $0.001-10$ & [38] \\
\hline $\begin{array}{l}\text { ELISA with the enzyme-like activity of Au@Pt } \\
\text { nanodendrites }\end{array}$ & $\begin{array}{c}\text { Combining signals of temperature, color and } \\
\text { fluorescence. }\end{array}$ & $3.4 \times 10^{-1}$ & $0.5-5.0$ & [39] \\
\hline ELISA with Pd-Ir nanocubes & CDs and fluorescent oxOPD & $3.1 \times 10^{-2}$ & $0.001-1.0$ & [40] \\
\hline NIFA & Fluorescent single-walled CNT & 100 & $0-2500$ & [19] \\
\hline Detection on pGold chip using SIA & A pGold chip-based platform & $1.0 \times 10^{-2}$ & $0.01-1.2$ & [18] \\
\hline MNPmediated-SPR & $\mathrm{Fe}_{3} \mathrm{O}_{4} \mathrm{MNP}$ & $7.2 \times 10^{-1}$ & $1.0-20.0$ & [24] \\
\hline Photoelectrochemical immunosensing & CdAgTe quantum dots and dodecahedral AuNPs & $1.7 \times 10^{-3}$ & $0.005-0.02$ & [25] \\
\hline Single-step LFIA & $\begin{array}{l}\text { Microfluidic chip instrumented with two microfluidic } \\
\text { modules }\end{array}$ & 4.0 & $0.01-1000$ & [41] \\
\hline $\begin{array}{c}\text { RTDIA based on a novel differential bright field } \\
\text { imaging system }\end{array}$ & Gold nanoparticles (AuNPs) & $5.7 \times 10^{-3}$ & $0-5000$ & [26] \\
\hline ECL immunosensing & Polyethylenimine-functionalized graphene electrode & $3.3 \times 10^{-2}$ & $0.005-30$ & [42] \\
\hline
\end{tabular}

a Abbreviations: FSIA—Fluorescent sandwich immunoassay, RCA—Rolling circle amplification, SIA—sandwich Immunoassay, AbsAntibodies, $\mathrm{cAb}$ - capture antibody, dAb—detection antibody, CNT—carbon nanotubes, LFIA—Lateral flow immunoassay, NIFA-Nearinfrared fluorescent assay, QDs-Quantum dots, MOF-Metal-organic framework PoC—Point-of-care, FRET—Fluorescence resonance energy transfer, ECL- Electrochemiluminescence, AuNPs-gold nanoparticles, CDs-Carbon dots, MNP-Magnetic nanoparticle, pGoldplasmonic gold nano-island, MIA—Magnetic immunoassay, NLISA-Nanoceria-linked immunosorbent assay, SPR—Surface plasmon resonance, RTDIA-Real-time digital immunoassay. 


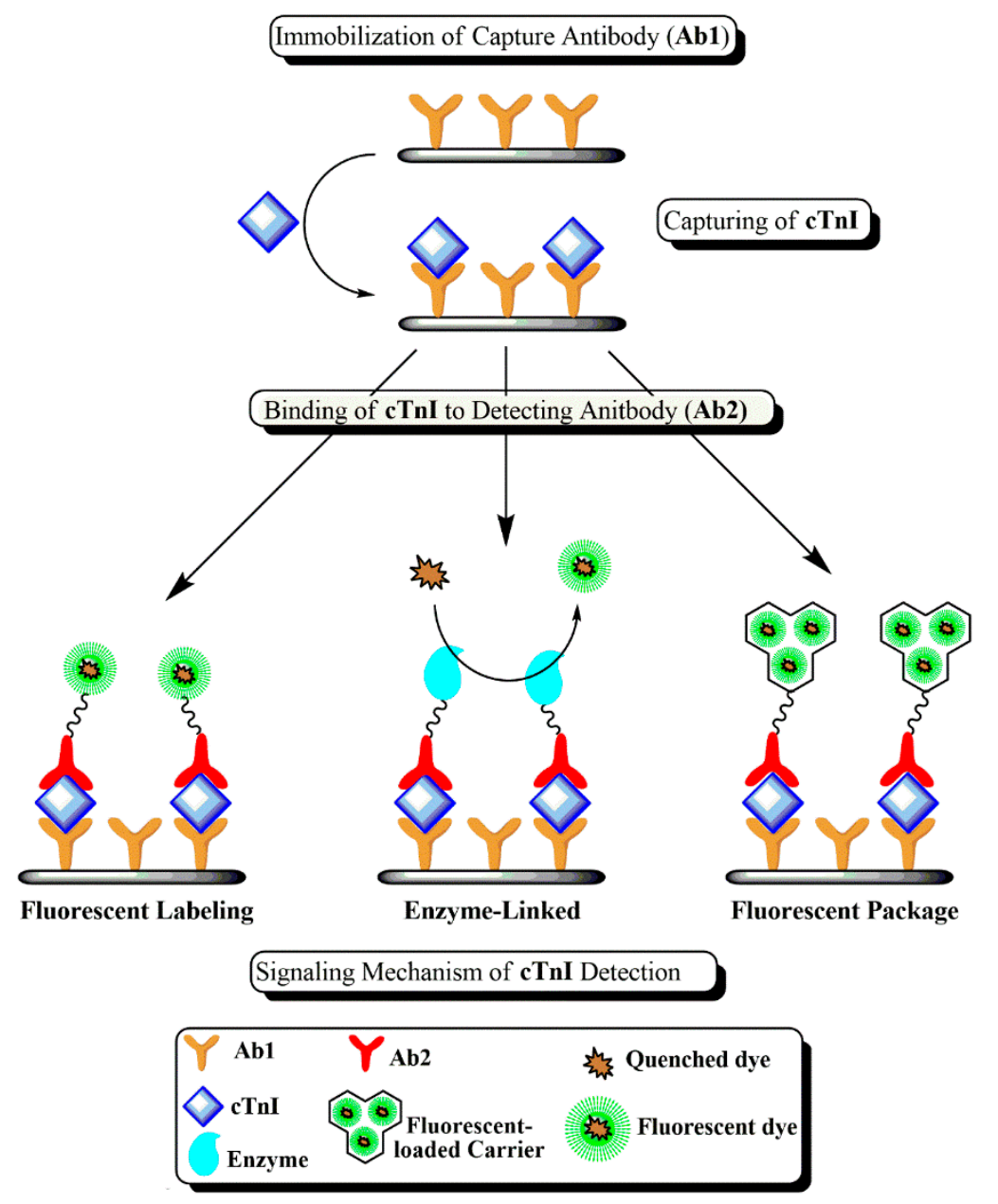

Scheme 1. Schematic representation of sandwich immunoassay design and steps.

\section{Signaling and Amplification Mechanisms}

\subsection{Direct Fluorescent Labeling}

The detection mechanism of this class of assays is based on a fluorescent label either directly conjugated to the detection antibody or subsequently added to the detection antibody after the binding event. Thus, for this class of assays, the fluorescence signal of antigen-antibody binding event is limited to that of the label directly conjugated to the antibody. For example, a study reported by Jiang et al. [28] described a sandwich immunoassay for cTnI, captured between an antibody immobilized on magnetic nanoparticles and a biotin-conjugated detection antibody. The fluorescent signal of streptavidin-conjugated quantum dots (QDs) is used to signal the presence of cTnI upon binding to biotin. The detection limit of the assay was $0.047 \mathrm{ng} / \mathrm{mL}$ and with a range of $0-40 \mathrm{ng} / \mathrm{mL}$. While this assay is sensitive enough to detect abnormal levels ( $>5 \mathrm{ng} / \mathrm{mL}$ ) of cTnI, its LDR is too narrow to reflect the extent of MI, which produces much higher concentrations of $\mathrm{cTnI}$ in the patient's blood.

Another example of an extended type of sandwich cTnI immunoassay uses threedimensional (3D) nanotube arrays of $\mathrm{TiO}_{2}$ to immobilize a polyclonal anti-troponin antibody where $\mathrm{cTnI}$ is captured. This $3 \mathrm{D}$ immobilization platform increases the concentration of the capture antibody on the surface, which helps to lower the LOD of the assay. Following the antigen-primary antibody interaction, there is the binding with a secondary antibody that, subsequently, binds to a fluorophore-labeled (AM700) tertiary antibody. The fluorescence emission is then proportional to cTnI levels that could be detected at concentrations as low as $0.1 \mathrm{pg} / \mathrm{mL}$ [31], however, the LDR of the assay $0.1-1 \mathrm{ng} / \mathrm{mL}$. This 
LDR makes the assay not relevant for quantification of cTnI at clinical applications unless the samples undergo a series of dilutions.

A similar approach of signal amplification based on the fluorescent of Alexa Fluorconjugated detection was reported recently for lateral flow immunoassay (LFIA). The capturing antibody is immobilized on cellulose nanofibers (CNFs) over a paper platform where CNFs help increase the number of capture antibodies on the surfaces (similar to 3D $\mathrm{TiO}_{2}$ nanotubes above). This enhances the sensitivity of this sandwich immunoassay for visual detection of the fluorescent signal. However, the LDR of $2.10-2.75 \mathrm{ng} / \mathrm{mL}$ renders the assay technically not useful for practical applications in clinical settings [43].

Lou et al. introduced a similar example of lateral flow immunoassay (LFIA) but the detection antibody and the fluorescent label are conjugated to a nanosphere [29]. The nanosphere is layered with biotinylated BSA, followed by fluorescent-labeled (Alexa Fluor 647) streptavidin, and then by biotinylated detection antibody. The lateral flow immunoassay (LFIA) starts by capturing cTnI on a nitrocellulose pad coated with capturing antibody. The functionalized labeled nanospheres are then accumulated on the antigen and, hence, the fluorescent signal intensity is enhanced. The LFIA exhibited high cTnI detection sensitivity (LOD of $0.049 \mathrm{ng} / \mathrm{mL}$ ) with LDR of $0.049-50.0 \mathrm{ng} / \mathrm{mL}$. This detection range enables the application of this assay into the clinical test but it may require dilutions for a blood sample that has high levels of cTnI.

Liu and co-researchers introduced a simple cTnI quantifying fluorescent assaybased on the competitive binding of the fluorescent-labeled aptamer to cTnI vs. graphene oxide (GO) surface. This assay is not a sandwich immunoassay and it does not require the use of any antibodies or immobilizing surface for capturing the antigen. Instead, in the absence of the protein, the aptasensor labeled with 6-carboxyfluorescein (6-FAM) binds to the GO surface, which quenches its fluorescence. Upon introducing cTnI, the aptamer binds to the protein preferably and separates from the GO surface, which turns on the fluorescence of 6-FAM. The enhancement of the fluorescence intensity in correlation to cTnI levels is the key detection mode. This novel assay exhibited high selectivity to cTnI compared with other interference proteins (HSA, BSA, IgA, IgG, and AFP) in the range of 0.10-6.0 ng $/ \mathrm{mL}$ and a low detection limit of $0.07 \mathrm{ng} / \mathrm{mL}$ [30]. Although this assay is simple and quick to apply with high selectivity, the narrow LDR limits its practical applications.

\subsection{Package of Fluorescent Labels}

On the other hand, Järvenpää et al. reported a single-step two-site cTnI sandwich immunoassay where europium(III)-chelate-dyed nanoparticles are used as the fluorescent label [33]. This strategy amplifies the signal for each antibody-antigen binding event because the concentration of the fluorescent label on the surface of the nanoparticle is much larger than the concentration of the label directly conjugated to the detection antibody (as in (i) above). The assay employs streptavidin-coated microtiter wells immobilized with a biotinylated monoclonal antibody and an enzymatically digested $\mathrm{F}\left(\mathrm{ab}^{\prime}\right) 2$ antibody. The quantification of cTnI is then attained by the simultaneous addition of the cTnI sample and the nanoparticles-conjugated capture antibody followed by measuring the fluorescence of the europium-bound nanoparticle (also known as "lanthanide luminescence"). The assay has an LOD of $0.0020 \mathrm{ng} / \mathrm{mL}$, a limit of quantification of $0.012 \mathrm{ng} / \mathrm{mL}$, and an LDR of $0.003-9.6 \mathrm{ng} / \mathrm{mL}$; this detection range is not practical for clinical settings.

Another way of increasing the concentration of fluorescent labels per binding event is by introducing a large load of fluorescent dyes. This was achieved by Wang et al. using coumarin (COU)-loaded metal-organic frameworks (MOFs), which have a high loading capacity of molecules because of their high porosity and surface area. Hence, the detection of cTnI by an antibody conjugated to a COU-loaded ZIF-8 MOFs (MOF@COU/Ab) amplifies the detection signal via the release of alkaline-hydrolyzed COU (green-blue fluorescence) from the MOFs' interior (Scheme 2). The fluorescence intensity is quantitatively related to the amount of cTnI captured providing a wide dynamic detection range of $0.026 \mathrm{ng} / \mathrm{mL}$ 
to $0.85 \mathrm{ng} / \mathrm{mL}$ with an LOD of $0.1 \mathrm{ng} / \mathrm{mL}$ [32]. This assay is then not suitable for the measurement of cTnI patients with a series of dilutions.<smiles>O=c1ccc2ccccc2o1</smiles>

coumarin

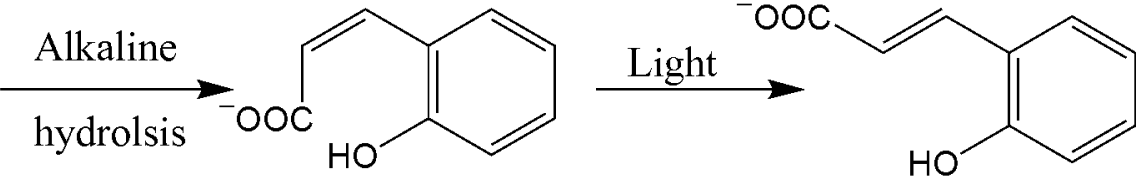

Fluorescent

Scheme 2. Hydrolysis of coumarin.

A more recent example of fluorescent-loaded anti-cTnI was reported by He and coworkers where acridinium ester-loaded into poly[( $N$-isopropyl acryl-amide)-co-(methacrylic acid)] (P(NIPAM-co-MAA)) microspheres were conjugated to detection antibody [44]. The capture antibody is immobilized on magnetic fluorescent nanobeads. After $\mathrm{cTnI}$ is sandwiched between the capturing and detecting antibodies, the solution is heated so that the acridinium ester is released from the microspheres and hydrolyzed to produce a chemiluminescent signal (Scheme 3) in addition to the fluorescent signal of the magnetic nanobeads. The LOD of $0.116 \mathrm{pg} / \mathrm{mL}$ and an LDR of $0.1-40 \mathrm{ng} / \mathrm{mL}$, which are relevant for the clinical settings.<smiles>[R]c1ccc(OC(=O)c2c3ccccc3[n+]([R])c3ccccc23)cc1</smiles>

Acridinium ester<smiles>[R]c1ccc(Oc2cccc3c2N([R])C2C=CC=CC3C2=[O+])cc1</smiles>

Scheme 3. Oxidation of acridinium ester.

Along the line of increasing fluorescent label density per binding event, Li et al. reported [34] a developed form of his aptamer assay by using a sandwich immunoassay whereby the detection antibody is replaced by aptamer-primer with a padlock probe for rolling circle amplification (RCA). The assay uses a simple microplate antibody-antigen reaction followed by RCA to generate a complementary strand for FAM nucleotide. The fluorescent probe is then released from the surface of graphene oxide and hybridized with the RCA product leading to amplified enhancement of the fluorescent signal with a detection limit as low as $14.40 \mathrm{pg} / \mathrm{mL}$ and an LDR range of $0.050-0.5 \mathrm{ng} / \mathrm{mL}$ [34].

In 2020, the same researchers developed an aptamer-based immunoassay coupled with a molecular beacon fluorescent probe and rolling circle amplification (RCA) for the accurate and sensitive detection of cTnI. In this strategy, the aptamer can act as a communication bridge between proteins and oligonucleotides. RCA amplification produces a circular template which is detected by fluorescence molecular beacon probe. This new method 
provides the specific and sensitive determination of cTnI with a limit of detection of $7.24 \mathrm{pg} / \mathrm{mL}[45]$.

\subsection{Enzyme-Linked Assays}

Enzyme-linked immunoassays are based on signal amplification by the catalytic activity of the enzyme to produce fluorescent products. Hence, each antibody-antigen binding event by enzyme-conjugated antibody produces a high concentration of the fluorescent label (even larger than that of (ii) above). The concentration of the antigen is then reflected through the generated fluorescent signal of the product. The disadvantage of this amplification process, however, is the need to monitor the signal over a specific (short) period. Otherwise, even with low concentrations of antigen, the signal can still saturate due to the high catalytic activity of the enzyme.

Liu and coworkers reported the use of alkaline phosphatase (ALP) to produce the non-fluorescent $p$-aminophenol which upon reaction with ethylene diamine produces fluorescent polymer carbon dots to detect $\mathrm{CTnI}$ at a wide concentration range with LDR of 1.0-30.0 ng/mL and an LOD of $1.0 \mathrm{ng} / \mathrm{mL}$ [37]. A similar strategy for using ALP was also reported by Zhao et al. [35] where ALP-mediated hydrolysis of $m$-hydroxyphenyl phosphate sodium salt produces a non-fluorescent product (resorcinol). The product then undergoes a nucleophilic reaction with dopamine to produce azamonardine, which is both chromogenic and fluorogenic (Scheme 4). The assay was sensitive enough to give an LOD of $0.04 \mathrm{ng} / \mathrm{mL}$ and LDR of $0.125-8.0 \mathrm{ng} / \mathrm{mL}$ [35].

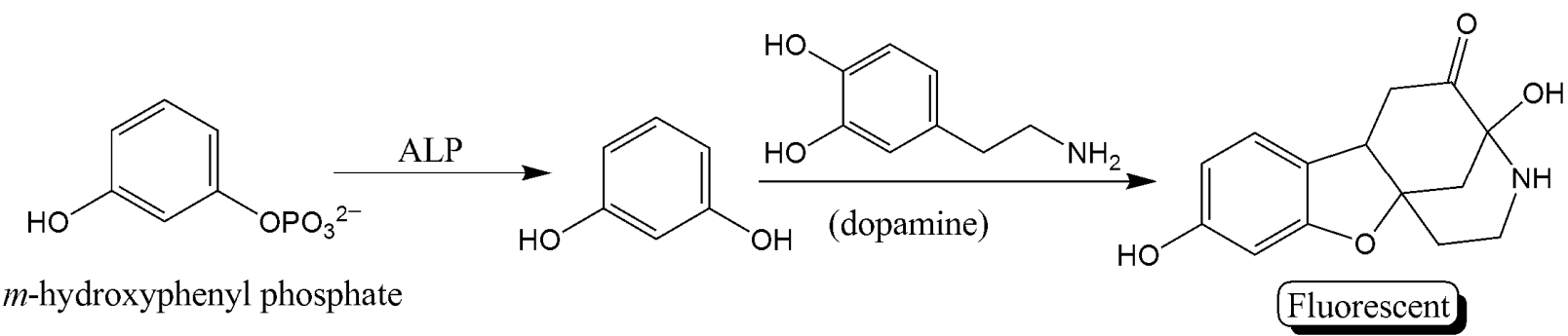

Scheme 4. Reaction scheme for the formation of fluorescent azamonardine.

The catalytic activity of certain nanoparticles was also utilized in enzyme-like activity for immunoassay. Miao et al. utilized the peroxidase-like properties of nanoceria to catalyze the oxidative conversion of o-phenylenediamine (OPD) into 2,3-diaminophenazine (ox-OPD) (Scheme 5) for dual colorimetric and ratiometric fluorescent signals detection modes. The effective fluorescence quenching of graphene QDs by the product results in a fluorescence spectral line with dual emission peaks in addition to a visible color change from colorless to orange [38]. The assay had a low $\operatorname{LOD}\left(2.3 \times 10^{-4} \mathrm{ng} / \mathrm{mL}\right)$ but with an LDR $(0.001-10 \mathrm{ng} / \mathrm{mL})$ lower than clinical concentrations of cTnI.<smiles>Nc1ccccc1N</smiles><smiles>Nc1cc2nc3ccccc3nc2cc1O</smiles>

Scheme 5. Oxidation product of o-phenylenediamine.

Another example of "artificial" enzymes apply the enzyme-like activity of Au@Pt nanodendrites. After capturing of cTnI and detection by Au@Pt nanodendrites-conjugated antibody, three methods are used to develop a signal that is directly dependent on cTnI concentration in solution. The first method, irradiation of the solution with a laser at 
$808 \mathrm{~nm}$ increases the temperature of the solution and it can be measured by a handheld thermometer. For the other two modes, the addition of OPD substrate to the solution in presence of $\mathrm{H}_{2} \mathrm{O}_{2}$ leads to its oxidation by $\mathrm{Au} @ \mathrm{Pt}$ nanodendrites to oxidized OPD (ox-OPD) (Scheme 5) which can be detected by either a yellow color or an increase in fluorescence intensity at $580 \mathrm{~nm}$ upon introduction of highly fluorescent carbon dots [39]. With a similar strategy, Tan et al. used Pd-Ir nanocubes to oxidize the nonfluorescent OPD to the fluorescent oxide product (oxOPD) in presence of $\mathrm{H}_{2} \mathrm{O}_{2}$. The sandwiched immunoassay with this dual detection signal has an LOD of $0.31 \mathrm{pg} / \mathrm{mL}$ and an LDR of $0.001-1.0 \mathrm{ng} / \mathrm{mL}$ for cTnI [40].

\section{Conclusions}

The presented survey of recently reported methods for the development of an immunoassay to quantify cTnI in blood has revealed that fluorescent-based sandwich immunoassays are effective and sensitive for quantification of cTnI over several platforms. The heterogeneous matrix in these assays provides a platform for minimizing interference by other biological molecules in the samples, yet it may increase the complexity and length of the assay. On the other hand, the increase in sensitivity and the decrease in LOD were accompanied for most cases with an LDR, which falls below the relevant clinical concentrations of cTnI in patients' blood. This brings another challenge to the ability to apply these assays in PoC testing or resource-scared settings, as it requires sample preparations and dilutions. Moreover, most of the reported assays require several steps of solution addition and washing, which increases the time needed to complete the assays.

The assays with direct fluorescent labels provide a quick detection assay; these are not very sensitive but their narrow LDRs fall within the clinical concentrations. The LOD decreases when a package of fluorescent labels is applied, yet the LDR generally falls into the sub-nano concentrations. On the other hand, the enzyme-linked assays are the most familiar assays and they generally provide an LDR within the needed range but these require time-control to avoid overestimation and false positives. Thus, the development of a quick and sensitive immunoassay for $\mathrm{CTnI}$ remains the future goal for many groups and research activities. There is a need to develop assays that are sensitive, specific and work at a wide dynamic range that covers the possible concentration of cTnI in patients' blood with possible MI (5-500 ng/mL). It is important that the assay works with direct blood samples without the need for sample processing and can be applied in PoC settings. The latter requires that the assay can be completed within a short time (minutes rather than hours) and with minimal use of lab equipment.

Author Contributions: All authors listed, have made extensive, direct and knowledgeable contributions to the write-up, and approved it for publication. Data curation and writing-original draft preparation, R.R. and S.K.S.; conceptualization, visualization, supervision, funding acquisition, and writing-review and editing, M.H.A.-S. All authors have read and agreed to the published version of the manuscript.

Funding: Funding was provided by the American University of Sharjah, UAE (grant \# BBRI18-CAS-05).

Acknowledgments: The authors acknowledge the technical and logistics support of the BCE Department and the Office of Research at the American University of Sharjah, UAE.

Conflicts of Interest: The authors declare there are no conflict of interests associated.

Disclosure: This paper represents the opinions of the authors and does not mean to represent the position or opinions of the American University of Sharjah.

\section{References}

1. Smiseth, O.A.; Tendera, M. (Eds.) Diastolic Heart Failure; Springer: London, UK, 2008; ISBN 978-1-84628-890-6.

2. WHO. WHO Global Status Report on Noncommunicable Diseases 2014; World Health Organization: Geneva, Switzerland, 2014.

3. Taherinia, A.; Ahmadi, K.; Bahramian, M.; Khademhosseini, P.; Taleshi, Z.; Maghsoudi, M.; Sattarzadeh Badkoubeh, R.; Talebian, M.T.; Rezaee, M. Diagnostic value of standard electrocardiogram in acute right ventricular myocardial infarction. Eur. J. Transl. Myol. 2019, 29, 8184. [CrossRef] 
4. Han, X.; Li, S.; Peng, Z.; Othman, A.M.; Leblanc, R. Recent development of cardiac Troponin I detection. ACS Sens. 2016, 1, 106-114. [CrossRef]

5. Sharma, S. Cardiac troponins. J. Clin. Pathol. 2004, 57, 1025-1026. [CrossRef]

6. Takeda, S.; Yamashita, A.; Maeda, K.; Maéda, Y. Structure of the core domain of human cardiac troponin in the Ca2 ${ }^{+}$-saturated form. Nature 2003, 424, 35-41. [CrossRef] [PubMed]

7. Guy, M.J.; Chen, Y.-C.; Clinton, L.; Zhang, H.; Zhang, J.; Dong, X.; Xu, Q.; Ayaz-Guner, S.; Ge, Y. The impact of antibody selection on the detection of cardiac Troponin I. Clin. Chim. Acta 2013, 420, 82-88. [CrossRef]

8. Amundson, B.E.; Apple, F.S. Cardiac troponin assays: A review of quantitative point-of-care devices and their efficacy in the diagnosis of myocardial infarction. Clin. Chem. Lab. Med. CCLM 2015, 53, 665-676. [CrossRef]

9. Marston, S.; Zamora, J.E. Troponin structure and function: A view of recent progress. J. Muscle Res. Cell Motil. 2020, 41, 71-89. [CrossRef] [PubMed]

10. Cheng, Y.; Regnier, M. Cardiac troponin structure-function and the influence of hypertrophic cardiomyopathy associated mutations on modulation of contractility. Arch. Biochem. Biophys. 2016, 601, 11-21. [CrossRef]

11. Melanson, S.E.F.; Tanasijevic, M.J.; Jarolim, P. Cardiac troponin assays: A view from the clinical chemistry laboratory. Circulation 2007, 116, e501-e504. [CrossRef]

12. Haushalter, K.J.; Vetcha, S.; Haushalter, R.C. Multiplex flow assays. ACS Omega 2016, 1, 586-599. [CrossRef]

13. Ju, H.; Zhang, X.; Wang, J. Biological and Medical Physics, Biomedical Engineering. In NanoBiosensing: Principles, Development and Application; Springer: New York, NY, USA, 2011; ISBN 978-1-4419-9621-3.

14. Lee, K.H.; Park, H.; Hwang, M. Immunomagnetic nanoparticle-based assays for detection of biomarkers. Int. J. Nanomed. 2013, 8, 4543. [CrossRef] [PubMed]

15. Mayilo, S.; Kloster, M.A.; Wunderlich, M.; Lutich, A.; Klar, T.A.; Nichtl, A.; Kürzinger, K.; Stefani, F.D.; Feldmann, J. Long-range fluorescence quenching by gold nanoparticles in a sandwich immunoassay for cardiac Troponin T. Nano Lett. 2009, 9, 4558-4563. [CrossRef]

16. Singal, S.; Srivastava, A.K.; Gahtori, B. Rajesh immunoassay for Troponin I using a glassy carbon electrode modified with a hybrid film consisting of graphene and multiwalled carbon nanotubes and decorated with platinum nanoparticles. Microchim. Acta 2016, 183, 1375-1384. [CrossRef]

17. Zhu, J.; Zou, N.; Zhu, D.; Wang, J.; Jin, Q.; Zhao, J.; Mao, H. Simultaneous detection of high-sensitivity cardiac Troponin I and myoglobin by modified sandwich lateral flow immunoassay: Proof of principle. Clin. Chem. 2011, 57, 1732-1738. [CrossRef]

18. Xu, W.; Wang, L.; Zhang, R.; Sun, X.; Huang, L.; Su, H.; Wei, X.; Chen, C.-C.; Lou, J.; Dai, H.; et al. Diagnosis and prognosis of myocardial infarction on a plasmonic chip. Nat. Commun. 2020, 11, 1654. [CrossRef]

19. Zhang, J.; Kruss, S.; Hilmer, A.J.; Shimizu, S.; Schmois, Z.; De La Cruz, F.; Barone, P.W.; Reuel, N.F.; Heller, D.A.; Strano, M.S. A rapid, direct, quantitative, and label-free detector of cardiac biomarker Troponin $\mathrm{T}$ using near-infrared fluorescent single-walled carbon nanotube sensors. Adv. Healthc. Mater. 2014, 3, 412-423. [CrossRef] [PubMed]

20. Cho, J.-H.; Kim, M.-H.; Mok, R.-S.; Jeon, J.-W.; Lim, G.-S.; Chai, C.-Y.; Paek, S.-H. Two-dimensional paper chromatography-based fluorescent immunosensor for detecting acute myocardial infarction markers. J. Chromatogr. B 2014, 967, 139-146. [CrossRef]

21. Rodenko, O.; Eriksson, S.; Tidemand-Lichtenberg, P.; Troldborg, C.P.; Fodgaard, H.; van Os, S.; Pedersen, C. High-sensitivity detection of cardiac Troponin I with UV LED excitation for use in point-of-care immunoassay. Biomed. Opt. Express 2017, 8, 3749. [CrossRef]

22. Lee, S.; Kang, S.H. Quenching effect on gold nano-patterned cardiac Troponin I chip by total internal reflection fluorescence microscopy. Talanta 2013, 104, 32-38. [CrossRef]

23. Lopez-Calle, E.; Espindola, P.; Spinke, J.; Lutz, S.; Nichtl, A.; Tgetgel, A.; Herbert, N.; Marcinowski, M.; Klepp, J.; Fischer, T.; et al. A new immunochemistry platform for a guideline-compliant cardiac Troponin T assay at the point of care: Proof of principle. Clin. Chem. Lab. Med. CCLM 2017, 55, 1798-1804. [CrossRef]

24. Tang, L.; Casas, J.; Venkataramasubramani, M. Magnetic nanoparticle mediated enhancement of localized surface plasmon resonance for ultrasensitive bioanalytical assay in human blood plasma. Anal. Chem. 2013, 85, 1431-1439. [CrossRef] [PubMed]

25. Tan, Y.; Wang, Y.; Li, M.; Ye, X.; Wu, T.; Li, C. Enhanced photoelectrochemical immunosensing of cardiac Troponin I based on energy transfer between N-Acetyl-L-Cysteine capped CdAgTe quantum dots and dodecahedral Au nanoparticles. Biosens. Bioelectron. 2017, 91, 741-746. [CrossRef]

26. Wang, Y.; Yang, Y.; Chen, C.; Wang, S.; Wang, H.; Jing, W.; Tao, N. One-step digital immunoassay for rapid and sensitive detection of cardiac Troponin I. ACS Sens. 2020, 5, 1126-1131. [CrossRef]

27. Braga, F.; Aloisio, E.; Panzeri, A.; Nakagawa, T.; Panteghini, M. Analytical validation of a highly sensitive point-of-care system for cardiac Troponin I determination. Clin. Chem. Lab. Med. CCLM 2019, 58, 138-145. [CrossRef]

28. Jiang, H.; Zhu, J.; Liu, W.; Cao, F. High-sensitivity cardiac Troponins I sandwich assay by immunomagnetic microparticle and quantum dots. Front. Lab. Med. 2017, 1, 107-113. [CrossRef]

29. Lou, D.; Fan, L.; Ji, Y.; Gu, N.; Zhang, Y. A Signal amplifying fluorescent nanoprobe and lateral flow assay for ultrasensitive detection of cardiac biomarker Troponin I. Anal. Methods 2019, 11, 3506-3513. [CrossRef]

30. Liu, D.; Lu, X.; Yang, Y.; Zhai, Y.; Zhang, J.; Li, L. A novel fluorescent aptasensor for the highly sensitive and selective detection of cardiac Troponin I based on a graphene oxide platform. Anal. Bioanal. Chem. 2018, 410, 4285-4291. [CrossRef] [PubMed] 
31. Kar, P.; Pandey, A.; Greer, J.J.; Shankar, K. Ultrahigh sensitivity assays for human cardiac Troponin I using TiO2 nanotube arrays. Lab. Chip 2012, 12, 821. [CrossRef]

32. Wang, X.; Wang, X.; Han, Y.; Li, H.; Kang, Q.; Wang, P.; Zhou, F. Immunoassay for cardiac Troponin I with fluorescent signal amplification by hydrolyzed coumarin released from a metal-organic framework. ACS Appl. Nano Mater. 2019, 2, 7170-7177. [CrossRef]

33. Järvenpää, M.-L.; Kuningas, K.; Niemi, I.; Hedberg, P.; Ristiniemi, N.; Pettersson, K.; Lövgren, T. Rapid and sensitive cardiac Troponin I immunoassay based on fluorescent europium(III)-chelate-dyed nanoparticles. Clin. Chim. Acta 2012, 414, 70-75. [CrossRef] [PubMed]

34. Li, Y.; Dai, W.; Lv, X.; Deng, Y. Aptamer-based rolling circle amplification coupled with graphene oxide-based fluorescence resonance energy transfer for sensitive detection of cardiac Troponin I. Anal. Methods 2018, 10, 1767-1773. [CrossRef]

35. Zhao, J.; Wang, S.; Lu, S.; Liu, G.; Sun, J.; Yang, X. Fluorometric and colorimetric dual-readout immunoassay based on an alkaline phosphatase-triggered reaction. Anal. Chem. 2019, 91, 7828-7834. [CrossRef] [PubMed]

36. Liu, J.; Zhang, L.; Wang, Y.; Zheng, Y.; Sun, S. An improved portable biosensing system based on enzymatic Chemiluminescence and magnetic immunoassay for biological compound detection. Measurement 2014, 47, 200-206. [CrossRef]

37. Liu, G.; Zhao, J.; Wang, S.; Lu, S.; Sun, J.; Yang, X. Enzyme-induced in situ generation of polymer carbon dots for fluorescence immunoassay. Sens. Actuators B Chem. 2020, 306, 127583. [CrossRef]

38. Miao, L.; Jiao, L.; Tang, Q.; Li, H.; Zhang, L.; Wei, Q. A nanozyme-linked immunosorbent assay for dual-modal colorimetric and ratiometric fluorescent detection of cardiac Troponin I. Sens. Actuators B Chem. 2019, 288, 60-64. [CrossRef]

39. Jiao, L.; Zhang, L.; Du, W.; Li, H.; Yang, D.; Zhu, C. Au@Pt nanodendrites enhanced multimodal enzyme-linked Immunosorbent assay. Nanoscale 2019, 11, 8798-8802. [CrossRef]

40. Tan, X.; Zhang, L.; Tang, Q.; Zheng, G.; Li, H. Ratiometric fluorescent immunoassay for the cardiac Troponin-I using carbon dots and palladium-iridium nanocubes with peroxidase-mimicking activity. Microchim. Acta 2019, 186, 280. [CrossRef]

41. Hemmig, E.; Temiz, Y.; Gökçe, O.; Lovchik, R.D.; Delamarche, E. Transposing lateral flow immunoassays to capillary-driven microfluidics using self-coalescence modules and capillary-assembled receptor carriers. Anal. Chem. 2020, 92, 940-946. [CrossRef]

42. Tang, M.; Zhou, Z.; Shangguan, L.; Zhao, F.; Liu, S. Electrochemiluminescent detection of cardiac troponin I by using soybean peroxidase labeled-antibody as signal amplifier. Talanta 2018, 180, 47-53. [CrossRef] [PubMed]

43. Natarajan, S.; Jayaraj, J.; Prazeres, D.M.F. A cellulose paper-based fluorescent lateral flow immunoassay for the quantitative detection of cardiac Troponin I. Biosensors 2021, 11, 49. [CrossRef]

44. Zhao, H.; Lin, Q.; Huang, L.; Zhai, Y.; Liu, Y.; Deng, Y.; Su, E.; He, N. Ultrasensitive chemiluminescence immunoassay with enhanced precision for the detection of CTnI amplified by acridinium ester-loaded microspheres and internally calibrated by magnetic fluorescent nanoparticles. Nanoscale 2021, 13, 3275-3284. [CrossRef] [PubMed]

45. Li, Y.; Yang, Y.; Lü, X.; Deng, Y. Aptamer-based fluorescent assay for sensitive detection of cardiac Troponin I. J. Beijing Inst. Technol. 2020, 29, 45. 